\title{
PNA-FISH as a new diagnostic method for the determination of clarithromycin resistance of Helicobacter pylori
}

\author{
Laura Cerqueira', Ricardo M Fernandes ${ }^{1}$, Rui M Ferreira ${ }^{2,3}$, Fátima Carneiro ${ }^{2,3,4}$, Mário Dinis-Ribeiro ${ }^{3,5}$, \\ Céu Figueiredo ${ }^{2,3}$, Charles W Keevil ${ }^{6}$, Nuno F Azevedo ${ }^{1,7}$ and Maria J Vieira ${ }^{\text {* }^{*}}$
}

\begin{abstract}
Background: Triple therapy is the gold standard treatment for Helicobacter pylori eradication from the human stomach, but increased resistance to clarithromycin became the main factor of treatment failure. Until now, fastidious culturing methods are generally the method of choice to assess resistance status. In this study, a new genotypic method to detect clarithromycin resistance in clinical samples, based on fluorescent in situ hybridization (FISH) using a set of peptide nucleic acid probes (PNA), is proposed.

Results: The set of probes targeting the point mutations responsible for clarithromycin resistance was applied to H. pylori suspensions and showed $100 \%$ sensitivity and specificity $(95 \% \mathrm{Cl}, 79.9-100$ and $95 \% \mathrm{Cl}, 71.6-100$ respectively). This method can also be amenable for application to gastric biopsy samples, as resistance to clarithromycin was also detected when histological slides were tested.

Conclusions: The optimized PNA-FISH based diagnostic method to detect $\mathrm{H}$. pylori clarithromycin resistance shown to be a very sensitive and specific method for the detection of clarithromycin resistance in the $\mathrm{H}$. pylori smears and also proved to be a reliable method for the diagnosis of this pathogen in clinical samples and an alternative to existing plating methods.
\end{abstract}

\section{Background}

Helicobacter pylori is well known for its ability to colonize human stomach and, while most human carriers are asymptomatic, colonization can lead to the development of several gastric diseases, such as peptic ulcer disease, gastric mucosa-associated lymphoid tissue (MALT) lymphoma and gastric carcinoma.

The over-usage of antimicrobial compounds has led to an increase of $H$. pylori resistance to antibiotics and consequent failure in treatment therapy [1,2]. In accordance with the Maastricht Consensus in Europe, the recommended therapy for $H$. pylori eradication in the stomach mucosa is the use of a proton pump inhibitor associated with two antibiotics, such as metronidazole, amoxicillin or clarithromycin for a 7-14 days period [3].

\footnotetext{
* Correspondence: mjv@deb.uminho.pt

${ }^{1}$ IBB - Institute for Biotechnology and Bioengineering, Centre of Biological Engineering, Universidade do Minho, Campus de Gualtar 4710-057, Braga, Portugal

Full list of author information is available at the end of the article
}

This therapy, although highly effective, is unselectively proposed to all patients and can imply serious discomfort to patients due to side effects of the antibiotics. Clarithromycin resistance is one of the most prevalent and can reach up to $20 \%$ in Southern European countries [1]. The resistance is associated with point mutations in the peptidyltransferase region encoded in domain $\mathrm{V}$ of the $H$. pylori $23 \mathrm{~S}$ rRNA gene $[2,4,5]$. The three most prevalent point mutations are the transitions A2142G and A2143G and the transversion A2142C $[1,2,4]$. Until now, the antibiotic susceptibility has been detected in clinical laboratories by several phenotypical methods such as the agar dilution method, as recommended by the National Committee for Clinical Laboratory Standards (NCCLS) [6], or the alternative E-test that is considered to be more simple [7-10]. However, these methods are fastidious, time consuming [11], and fail to give any information about the point mutation within the sample [3]. Therefore, molecular methods for the detection of clarithromycin resistance in $H$. pylori
C Biomed Central

() 2011 Cerqueira et al; licensee BioMed Central Ltd. This is an Open Access article distributed under the terms of the Creative Commons Attribution License (http://creativecommons.org/licenses/by/2.0), which permits unrestricted use, distribution, and reproduction in any medium, provided the original work is properly cited. 
have been developed during the last several years in order to overcome these shortcomings. Polymerase chain reaction (PCR) followed by sequencing or reverse hybridization, Real-Time PCR and fluorescence in situ hybridization (FISH) with DNA probes are some examples $[2,9,12,13]$. When compared to PCR-based methods, the FISH technique presents some advantages since it is not so easily affected by DNA contamination, and allows for direct visualization of bacteria in the gastric biopsy specimens [1,2]. Recently, peptide nucleic acid (PNA) probes using FISH have been designed and optimized for the detection of several bacteria, such as Enterobacter sakazakii, Pseudomonas aeruginosa and Eschericia coli $[14,15]$. PNA molecules are DNA mimics that have the negatively charged sugar-phosphate backbone replaced by an achiral, neutral polyamide backbone formed by repetitive $\mathrm{N}$-(2-aminoethyl) glycine units $[16,17]$. Although PNA lacks pentoses, specific hybridization between the PNA sequences and nucleic acid complementary sequences still occur according to the Watson-Crick rules $[18,19]$. The neutral PNA molecule characteristic is responsible for a higher thermal stability (high Tm) between PNA/DNA or PNA/RNA bonding, compared with the traditional DNA probes [17]. Due to this high affinity, PNA probes normally have sequences relatively smaller (13-18 nucleotides) than DNA sequences (at least 18 nucleotides). Moreover, the PNA molecules present more resistance to nucleases and proteases than DNA molecules. When PNA probes are attached to a fluorochrome dye, they can be detected by epifluorescence microscopy or flow cytometry using the fluorescence in situ hybridization (FISH) method $[16,17,20]$. In earlier studies [19], this technique has provided more prompt and robust results in clinical and environmental samples than the traditional culture methods and it has been applied in a wide range of microbiology fields $[14,18]$. In fact, a PNA-FISH method to determine the presence of $H$. pylori in gastric biopsy specimens has been already developed in our laboratory, using a specific probe (Hp769) [21]. Due to the importance of antibiotic resistance, the aim of this work was to develop and validate a new PNA-FISH based diagnostic method to detect $H$. pylori clarithromycin resistance directly in paraffin embedded gastric biopsies.

\section{Methods}

\section{Bacterial strains and growth conditions}

Thirty three H. pylori strains (31 clinical isolates and 2 collection strains), that had their clarithromycin resistance profile determined in this study by sequencing and E-test (see method description below), were used. All strains were maintained on Columbia Agar Base (Liofilchem s.r.l., Roseto D.A., Italy) supplemented with $5 \%(\mathrm{vol} / \mathrm{vol})$ defibrinated horse blood (Probiológica,
Belas, Portugal). Single colonies were streaked onto fresh media every 2 or 3 days, and the plates were incubated in a $\mathrm{CO}_{2}$ incubator (HERAcell $150^{\circledR}$; Thermo Electron Corporation, Waltham, MA, USA) set to $10 \%$ $\mathrm{CO}_{2}$ and $5 \% \mathrm{O}_{2}$, at $37^{\circ} \mathrm{C}[21,22]$.

\section{Design of PNA oligonucleotide probes for the detection of clarithromycin resistance}

PNA probes were designed by adapting the already existing DNA probes, targeting the region of the point mutations described for this antibiotic in H. pylori [2]. Since PNA probes usually present higher melting temperatures it was possible to design shorter sequences with 15 nucleotides. The selected probes were $\mathrm{Hp} 1$ (A2143G) 5'-GGG TCT CTC CGT CTT-3', Hp2 (A2142G) 5'-GGG TCT TCC CGT CTT-3' and Hp3 (A2142C) 5'-GGG TCT TGC CGT CTT-3'. An additional probe to detect wild type strains (Hpwt 5'-GGG TCT TTC CGT CTT-3') was also included. Afterwards, the selected sequences were synthesized (Panagene, Daejeon, South Korea). The $\mathrm{N}$ terminus of the $\mathrm{Hp} 1, \mathrm{Hp} 2$ and $\mathrm{Hp} 3$ oligomers was connected to Alexa Fluor 488, and that of the Hpwt connected to Alexa Fluor 594, all via a double AminoEthoxyEthoxy Acetyl linker.

\section{Fluorescence in situ hybridization}

As a starting point for the optimization of hybridization conditions the protocol previously described was used $[14,21]$. Since the different probes only differed in one nucleobase, and for multiplex purposes, a common hybridization temperature was expected for all probes. Based on the brightest signals and specificity of the results, the best performance was obtained at $70^{\circ} \mathrm{C}$ (data not shown). H. pylori sensitive or resistant strain suspensions were prepared in water and $20 \mu \mathrm{l}$ of each suspension was dispensed in $8 \mathrm{~mm}$ well slides (Marienfeld, Lauda-Königshofen, Germany) and then allowed to air dry. For permeabilization and fixation of bacteria, $30 \mu \mathrm{l}$ of $4 \%$ paraformaldehyde (wt/vol) were placed in the wells with care to cover the entire surface, followed by $50 \%$ ( $\mathrm{vol} / \mathrm{vol}$ ) ethanol for 10 minutes each, and then allowed to air dry. Approximately $20 \mu \mathrm{l}$ of hybridization solution containing a mixture of the four probes were added to the fixed smears, which were then covered with coverslips and incubated for 1 hour at $70^{\circ} \mathrm{C}$. Each 1 $\mathrm{ml}$ of hybridization solution contained $200 \mathrm{nM}$ of the probes mixture, $10 \%$ (wt/vol) dextran sulphate, $10 \mathrm{mM}$ $\mathrm{NaCl}, 30 \%(\mathrm{v} / \mathrm{v})$ formamide, $0.1 \%$ (wt/vol) sodium pyrophosphate, $0.2 \%$ (wt/vol) polyvinylpyrrolidone, $0.2 \%$ (wt/ vol) FICOLL, $5 \mathrm{mM}$ disodium EDTA, 0.1\% (vol/vol) Triton $\mathrm{X}-100$ and $50 \mathrm{mM}$ Tris-HCl (all from SigmaAldrich, Sintra, Portugal, except disodium EDTA that was from Pronalab, Lisbon, Portugal). Subsequently, the slides were transferred to a Coplin jar containing 
prewarmed $\left(70^{\circ} \mathrm{C}\right)$ washing solution, that consisted of 5 $\mathrm{mM}$ Tris Base, $15 \mathrm{mM} \mathrm{NaCl}$ and $1 \%$ (vol/vol) Triton X100 (all from Sigma-Aldrich, Sintra, Portugal), where the coverslips were carefully removed. The washing step was carried out for 30 minutes at $70^{\circ} \mathrm{C}$. The slides were allowed to air dry and mounted with one drop of mounting oil and covered with a coverslip.

\section{Specificity and sensitivity of PNA probes}

After optimizing hybridization conditions, experiments with the PNA-FISH were performed on the 33 available strains in order to confirm the practical specificity and sensitivity of the probes. These results were compared with the gold standard susceptibility culturing test (Etest) and with the presence/absence of mutations in the 23S rRNA gene.

\section{Validation of the testing protocol in gastric biopsy slides for clinical application}

To validate the method in the stomach tissue, thirty nine paraffin-embedded gastric biopsy specimens from patients with known resistance antibiotic profile by antibiogram were used. The study was in accordance with the institutional ethical standards. Informed consent was obtained from the patients. Three-micrometer thick paraffin cuts were deparaffinized and rehydrated in xylol and ethanol based on a protocol previously described [21]. Sections were emerged in xylol (Fisher Chemical, Leicestershire, U.K.) three times (firstly for 15 minutes, and then twice for 10 minutes each), absolute ethanol (Panreac, Barcelona, Spain) (twice for 7.5 minutes each) and ethanol decreasing concentrations (95\%, twice for 7.5 minutes each; 80\%, 10 minutes; 70\%, 10 minutes; $50 \%$, twice for 15 minutes each). Finally sections were immersed in 1\% (vol/vol) Triton X-100 (Sigma-Aldrich, Sintra, Portugal) solution for 20 minutes at $70^{\circ} \mathrm{C}$. Histological slides were then allowed to air dry and the hybridization protocol previously described for smears, with the exclusion of the fixation step, was used. The completion of the whole procedure takes $4 \mathrm{~h} 15 \mathrm{~m}$.

\section{Susceptibly test: E-test}

In order to confirm the susceptibility profile, the minimal inhibitory concentration (MIC) of each strain was determined by the E-test, in accordance with the company instructions (AB Biodisk, Biomérieux, Portugal). Briefly, 2 day-old pure cultures were inoculated into Mueller-Hinton broth, supplemented with $5 \%$ (vol/vol) fetal calf serum [23] and the turbidity of the inoculum adjusted to McFarland standard 3 [7]. Agar plates containing Mueller-Hinton supplemented with 5\% (vol/vol) defibrinated horse blood (Probiológica, Belas, Portugal) were inoculated by swabbing the surface with the inocula. One E-test strip was applied on the surface of the plate, after drying. The plates were incubated in a $\mathrm{CO}_{2}$ incubator (HERAcell $150^{\circledR}$; Thermo Electron Corporation, Waltham, MA, USA) set to $10 \% \mathrm{CO}_{2}$ and $5 \%$ $\mathrm{O}_{2}$ at $37^{\circ} \mathrm{C}$ for $72 \mathrm{~h}$ or until visible inhibition ellipse was seen $[2,7,23]$. Strains were considered susceptible when the $\mathrm{MIC}$ was $<1 \mu \mathrm{g} / \mathrm{ml}$, and resistant when the MIC was $>1 \mu \mathrm{g} / \mathrm{ml}[9]$.

\section{Assessment of clarithromycin resistance in gastric tissues by PCR and sequencing}

Total DNA was extracted from biopsy samples after digestion with Proteinase $\mathrm{K}$ for at least 12 hours at $55^{\circ}$ C. Proteinase $\mathrm{K}$ was inactivated by incubation at $95^{\circ} \mathrm{C}$ for 10 minutes. Ten microliters of the lysates were used for PCR amplification of $H$. pylori 23S rRNA gene as previously described [24]. PCR products were sequenced using BigDye Terminator v3.1 Cycle Sequencing Kits (Applied Biosystems, CA, USA) and run in an ABI Prism 3130 DNA automated sequencer (Applied Biosystems). In some $H$. pylori isolates, PCR and sequencing were used to characterize the $23 \mathrm{~S}$ rRNA gene.

\section{Microscopic visualization}

Visualization of samples never exceeded $48 \mathrm{~h}$ after the experimental procedure. Smears or histological slides were observed using an epifluorescence microscope (BX51 Olympus, Hamburg, Germany) equipped with filters adapted to the Alexa Fluor (488 and 594) signalling molecules within the probes. The filters that were not sensitive for the reporter molecules were used as negative control.

\section{Results and Discussion}

\section{Specificity and sensitivity of the PNA-FISH probes}

In order to confirm the practical specificity and sensitivity of the probes, PNA-FISH was performed on the 33 available strains (table 1 ). The original genotyping of the strains was confirmed by sequencing, and 20 isolates were identified as clarithromycin resistant. Of these, 10 presented the A2143G mutation, eight the A2142G mutation and one the A2142C mutation. In one case, different genotypes in the same strain (WT and A2143G) were observed, and this strain was considered resistant. The comparison between PNA-FISH and sequencing showed a correlation of $100 \%$.

There are other less prevalent point mutations referred in the literature [25-28], but are surrounded by controversy since their association to clarithromycin resistance have not been definitely proved $[1,29]$. In addition to that, some reports presented clarithromycin resistance mechanisms other than point mutations, such as efflux pumps or rRNA methylation [30] that can be revealed with phenotypic methods, although they are not detected by genotypic methods that are specific to 
Table 1 PCR, E-test and FISH results of the detection of clarithromycin resistance in $\boldsymbol{H}$. pylori clinical isolates

\begin{tabular}{|c|c|c|c|c|}
\hline Strain & Genotype & PCR & E-test & PNA-FISH \\
\hline $3939^{1}$ & WT & $\mathrm{S}$ & $S$ & $\mathrm{~S}$ \\
\hline $2277^{1}$ & WT & $S$ & $\mathrm{R}$ & $\mathrm{S}$ \\
\hline $2406^{1}$ & WT & S & S & S \\
\hline $2424^{1}$ & WT & S & $S$ & S \\
\hline $3183^{1}$ & WT & S & $S$ & S \\
\hline $3131^{1}$ & WT & S & $\mathrm{S}$ & S \\
\hline $3148^{1}$ & WT & S & S & S \\
\hline $2452 A^{1}$ & WT & S & $S$ & $S$ \\
\hline $2448^{1}$ & WT & S & $S$ & S \\
\hline $2708^{1}$ & $\mathrm{~A} 2142 \mathrm{G}$ & $R$ & $\mathrm{R}$ & $\mathrm{R}$ \\
\hline $2712^{1}$ & $\mathrm{~A} 2142 \mathrm{G}$ & $\mathrm{R}$ & $\mathrm{R}$ & $\mathrm{R}$ \\
\hline $3941^{1}$ & WT/A2143G & $\mathrm{R}$ & $\mathrm{R}$ & $\mathrm{R}$ \\
\hline $2191^{1}$ & A2143G & $\mathrm{R}$ & $\mathrm{R}$ & $\mathrm{R}$ \\
\hline $2009^{1}$ & A2143G & $\mathrm{R}$ & $\mathrm{R}$ & $\mathrm{R}$ \\
\hline $1162^{1}$ & A2143G & $\mathrm{R}$ & $\mathrm{R}$ & $\mathrm{R}$ \\
\hline $1987^{1}$ & A2143G & $\mathrm{R}$ & $R$ & $\mathrm{R}$ \\
\hline $2053^{1}$ & A2143G & $\mathrm{R}$ & $\mathrm{R}$ & $\mathrm{R}$ \\
\hline $2538^{1}$ & A2143G & $\mathrm{R}$ & $\mathrm{R}$ & $\mathrm{R}$ \\
\hline $2539^{1}$ & A2143G & $\mathrm{R}$ & $\mathrm{R}$ & $\mathrm{R}$ \\
\hline $2768^{1}$ & A2143G & $\mathrm{R}$ & $\mathrm{R}$ & $\mathrm{R}$ \\
\hline $166^{2}$ & A2142C & $R$ & $\mathrm{R}$ & $R$ \\
\hline $167^{2}$ & A2143G & $\mathrm{R}$ & $\mathrm{R}$ & $\mathrm{R}$ \\
\hline $168^{2}$ & $\mathrm{~A} 2142 \mathrm{G}$ & $\mathrm{R}$ & $\mathrm{R}$ & $\mathrm{R}$ \\
\hline $169^{2}$ & WT & $\mathrm{S}$ & $S$ & $\mathrm{~S}$ \\
\hline $7.83^{3}$ & A2143G & $\mathrm{R}$ & $\mathrm{R}$ & $\mathrm{R}$ \\
\hline $7.11^{3}$ & A2142G & $R$ & $\mathrm{R}$ & $R$ \\
\hline $7.38^{3}$ & $\mathrm{~A} 2142 \mathrm{G}$ & $\mathrm{R}$ & $\mathrm{R}$ & $\mathrm{R}$ \\
\hline $6271^{3}$ & $\mathrm{~A} 2142 \mathrm{G}$ & $\mathrm{R}$ & $\mathrm{R}$ & $\mathrm{R}$ \\
\hline $7.36^{3}$ & $\mathrm{~A} 2142 \mathrm{G}$ & $\mathrm{R}$ & $R$ & $R$ \\
\hline $6231^{3}$ & $\mathrm{~A} 2142 \mathrm{G}$ & $\mathrm{R}$ & $\mathrm{R}$ & $\mathrm{R}$ \\
\hline $968^{1}$ & WT & S & $S$ & S \\
\hline NCTC $11637^{4}$ & WT & $S$ & $S$ & S \\
\hline ATCC $700392^{4}$ & WT & S & $S$ & $\mathrm{~S}$ \\
\hline
\end{tabular}

Some strains were also sequenced in our labs to guarantee that no contamination had occurred during culture maintenance

${ }^{1}$ Dr. M. Oleastro (National Institute of Health, Lisbon, Portugal); ${ }^{2}$ Dr. R. Haas (Max von Pettenkofer Institute for Hygiene and Medical Microbiology, Ludwig Maximilians University of Munich, Germany); ${ }^{3}$ Dr. G. Perez-Perez (NYU Langone Medical Center, New York, USA); ${ }^{4}$ Type strain; R: Clarithromycin resistant (MIC $>1 \mu \mathrm{g} / \mathrm{ml}$ ); S: Clarithromycin susceptible (MIC $<1 \mu \mathrm{g} / \mathrm{ml}$ ); WT: Wild Type.

certain cellular events as is the case of the probes here described. In the present manuscript, one of the strains tested gave different results between E-test (MIC $32 \mu \mathrm{g} /$ $\mathrm{ml}$ ) and PNA-FISH (only hybridized with the Hpwt) showing $95.5 \%$ of similarity between the two methods (table 2). This apparently discrepant observation may be attributed to the presence of other 23S rRNA gene mutations known to confer phenotypic resistance or, alternatively, to additional mechanisms of resistance. Despite this decrease in sensitivity, it is known that the
Table 2 Comparison between PNA-FISH methodology, PCR-sequencing and E-test for detection of clarithromycin resistance in $33 \mathrm{H}$. pylori strains

\begin{tabular}{lll}
\hline & PNA-FISH & \\
\cline { 2 - 3 } & Resistant & Susceptible \\
\hline E-test & 20 & 1 \\
Resistant (21) & 0 & 12 \\
Susceptible (12) & 20 & 0 \\
\hline PCR-sequencing & & 13 \\
Resistant (20) & 0 & 13 \\
Susceptible (13) & & \\
\hline
\end{tabular}

three mutations referred to in this study were revealed to be the more frequently associated with macrolide resistance. De Francesco and co-workers [30] stated that more than $90 \%$ of primary clarithromycin resistance strains from western countries are related with A2142G, A2142C and A2143G mutations.

From the three mutations, the one that is less frequent is the $\mathrm{A} 2142 \mathrm{C}$ transversion $[1,12]$, and in this study we were only able to test one strain with that mutation. Nevertheless, the available strain was always detected when the $\mathrm{Hp} 3$ probe was present in the hybridization solution. Probes $\mathrm{Hp} 1, \mathrm{Hp} 2$, and $\mathrm{Hp} 3$, hybridized only with the resistant strains that had the corresponding point mutations conferring clarithromycin resistance and as such presented $100 \%$ sensitivity (95\% CI, 79.9100 ) and $100 \%$ specificity (95\% CI, 71.6-100). The set of probes can discriminate the resistant and susceptible strains, even though they only have one mismatch. We next further tested the method using a mixture of the four probes simultaneously in a multiplex detection (figure $1 ; \mathrm{A}-\mathrm{C}$ ). In this case, the detection of point mutations was even more robust, which is possibly due to the fact that all probes target the same locus, and as such there is a competition effect between them. However, with the mixture it is only possible to discriminate between clarithromycin resistant and clarithromycin sensitive strains, as opposed to the discrimination between point mutations that was conferred by using the probes separately. In practical terms and considering the application of the PNA-FISH to the clinical setting, the mixture of probes introduces an important simplification to the method.

\section{Validation of the testing protocol in gastric biopsy slides} for clinical application

Considering the application of the PNA-FISH method in clinical settings, we used the developed PNA probes to identify and differentiate clarithromycin resistant and susceptible H. pylori strains in histological slides of gastric biopsy samples. Results clearly show that it is possible to discriminate susceptible from resistant $H$. pylori 

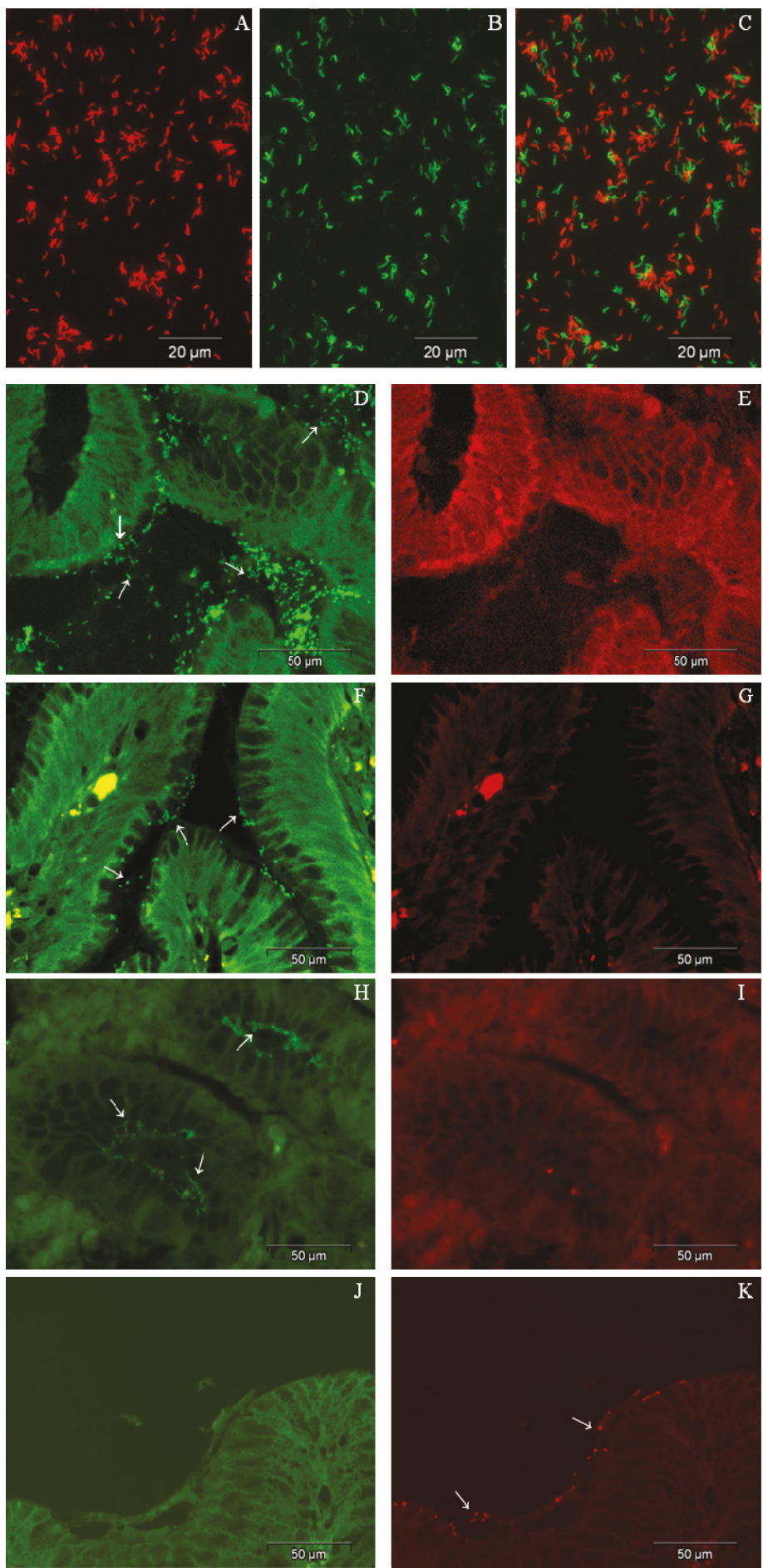

Figure 1 PNA-FISH detection. A)-C) In smears: A) Susceptible strain in the red channel; B) Resistant strain in the same microscopic field in the green channel; C) Superimposition of both channels. D)-K) In gastric biopsy histological slides. D) Strain visualization using the Hp1 (A2143G) PNA probe; F) Hp2 (A2142G) PNA probe; H) Hp3 (A2142C) PNA probe; K) Hpwt (wild type strain) PNA probe; E),G),I) Visualization of the same microscopic field of D),F),H) with the red channel (negative controls for Hp1, Hp2 and Hp3); J) Visualization of the same microscopic field of K) with the green channel (negative control for Hpwt). Arrows indicate the presence of $\mathrm{H}$. pylori infecting the gastric mucosa. (Original magnification $\times 600$ ) 
strains and, in the latter group, to detect the three different mutations, using fluorescence microscopy (figure 1; D-K). Taking into consideration the antibiogram as the gold standard, the PNA-FISH method showed specificity and sensitivity of $90.9 \%$ (95\% CI, 57.1-99.5) and 84.2\% (95\% CI, 59.5-95.8), respectively (data not shown). These can probably be explained by the existence of another mechanism of resistance apart from the three point mutations assessed in this study. In fact, association between A2142C, A2142G and A2143G mutations and clarithromycin resistance was defined as approximately $84 \%$ in a world wide data compilation [3].

Although, these results need to be confirmed in a larger series of cases, they indicate that PNA-FISH is applicable to clinical samples and may be useful for the selection of the most adequate antibiotic combination to be used for $H$. pylori eradication. Moreover, this method is simple to perform and the procedure is fast $(4 \mathrm{~h} 15$ $\mathrm{m}$ ), indicating that results can be provided to clinicians simultaneously with the histological diagnosis.

\section{Conclusions}

Resistance to antibiotics, namely to clarithromycin, is one of the causes of treatment failure in H. pylori eradication [1]. For this reason, it is the most beneficial to detect resistance to clarithromycin prior to antibiotic therapy. Standard culturing methods (E-test, agar dilution) have been used for this purpose, despite several shortcomings: these methods are time consuming and $H$. pylori is difficult to grow in culture; there is the risk of contamination of samples during transportation leading to overgrowth of other bacteria that may mask the growth of $\mathrm{H}$. pylori; these methods do not provide any information regarding the specific point mutation(s) in each resistant strain [12]. Other alternative molecular based methods require DNA extraction followed by PCR amplification and sequencing for the identification of the mutation(s) $[4,9,13]$.

Herein we describe the applicability of PNA-FISH methodology to clinical material, namely gastric biopsy samples $[2,21]$, thus overcoming the need of culturing steps and/or PCR/sequencing procedures and enabling rapid initiation of appropriate antibiotic therapy until culture confirmation can be obtained several days later [1]. Furthermore, the required equipment, a fluorescent microscope equipped with adequate filters for fluorochromes, is easy to handle for routine diagnostic purposes. For centres using routine cultures of $H$. pylori, the complementary use of PNA-FISH methodology to smears of bacteria will increase the sensitivity of the detection of resistant strains in clinical samples.

\section{Acknowledgements}

The authors would like to thank Dr. Rainer Haas (Max von Pettenkofer Institute for Hygiene and Medical Microbiology, Ludwig Maximilians
University of Munich, Germany), Dr. Guillermo Perez-Perez (NYU Langone Medical Center, New York, USA), and Dr. Mónica Oleastro (National Institute of Health, Lisbon, Portugal) for kindly providing most of the $\mathrm{H}$. pylori strains used in this study and Endoclab (Porto, Portugal). This work was supported by the Portuguese Institute Fundação para a Ciência e a Tecnologia (Ph.D. grant SFRH/BD/38124/2007) and project PTDC/BIA-MIC/108811/2008).

\section{Author details}

${ }^{1}$ IBB - Institute for Biotechnology and Bioengineering, Centre of Biological Engineering, Universidade do Minho, Campus de Gualtar 4710-057, Braga, Portugal. ${ }^{2}$ IPATIMUP - Institute of Molecular Pathology and Immunology of the University of Porto, Porto, Portugal. ${ }^{3}$ Medical Faculty of the University of Porto, Porto, Portugal. ${ }^{4}$ Hospital S. João, Department of Pathology, Porto, Portugal. ${ }^{5}$ Portuguese Oncology Institute Porto, Department

Gastroenterology, Porto, Portugal. ' ${ }^{6}$ Environmental Healthcare Unit, School of Biological Sciences, University of Southampton, Southampton, UK. 'LEPAE, Department of Chemical Engineering, Faculty of Engineering, University of Porto, Porto, Portugal.

\section{Authors' contributions}

LC conceived of the study and participated in its design and drafted the manuscript. Carried out the PNA probes design, PNA-FISH, E-test and PCRsequencing assays. RMF participated in the PNA-FISH assays and in the design of the study. RMF carried out the PCR-sequencing studies. FC participated in the design of the study and helped to draft the manuscript. MDR participated in the design of the study and helped to draft the manuscript. Provided the gastric samples for the study. CF participated in the design of the study, on the PCR-sequencing analysis, and helped to draft the manuscript. CWK participated in the design of the study and helped to draft the manuscript. NFA conceived of the study and participated in its design and coordination and helped to draft the manuscript. MJV conceived of the study and participated in its design and coordination and helped to draft the manuscript. All authors read and approved the final manuscript.

\section{Competing interests}

Authors LC, NFA and MJV are inventors on a patent application describing the four PNA probes reported here (PT PAT 40801-09). This is currently held by University of Minho (UM) which is a current employer of LC and MJV and a previous employer of NFA. All the other authors are aware of the patent, agreed with its submission and do not present any competing interest.

Received: 23 February 2011 Accepted: 14 May 2011

Published: 14 May 2011

\section{References}

1. Megraud F: $\mathrm{H}$ pylori antibiotic resistance: prevalence, importance, and advances in testing. Gut 2004, 53(9):1374-1384.

2. Trebesius K, Panthel K, Strobel S, Vogt K, Faller G, Kirchner T, Kist M, Heesemann J, Haas R: Rapid and specific detection of Helicobacter pylori macrolide resistance in gastric tissue by fluorescent in situ hybridisation. Gut 2000, 46(5):608-614.

3. Yilmaz O, Demiray E: Clinical role and importance of fluorescence in situ hybridization method in diagnosis of $\mathrm{H}$ pylori infection and determination of clarithromycin resistance in $\mathrm{H}$ pylori eradication therapy. World J Gastroenterol 2007, 13(5):671-675.

4. Versalovic J, Shortridge D, Kibler K, Griffy MV, Beyer J, Flamm RK, Tanaka SK, Graham DY, Go MF: Mutations in 23S rRNA are associated with clarithromycin resistance in Helicobacter pylori. Antimicrob Agents Chemother 1996, 40(2):477-480.

5. De Francesco V, Margiotta M, Zullo A, Hassan C, Giorgio F, Burattini O, Stoppino G, Cea U, Pace A, Zotti M, et al: Prevalence of primary clarithromycin resistance in Helicobacter pylori strains over a 15 year period in Italy. J Antimicrob Chemother 2007, 59(4):783-785.

6. National Committee for Clinical Laboratory Standards: Performance standards for antimicrobial susceptibility testing- Sixth informational supplement Wayne, Pa; 1999, M100 S9.19,1.

7. Piccolomini R, Di Bonaventura G, Catamo G, Carbone F, Neri M: Comparative evaluation of the $\mathrm{E}$ test, agar dilution, and broth microdilution for testing susceptibilities of Helicobacter pylori strains to 20 antimicrobial agents. J Clin Microbiol 1997, 35(7):1842-1846. 
8. Osato MS, Reddy R, Reddy SG, Penland RL, Graham DY: Comparison of the Etest and the NCCLS-approved agar dilution method to detect metronidazole and clarithromycin resistant Helicobacter pylori. Int J Antimicrob Agents 2001, 17(1):39-44.

9. Oleastro M, Menard A, Santos A, Lamouliatte H, Monteiro L, Barthelemy P, Megraud F: Real-time $P C R$ assay for rapid and accurate detection of point mutations conferring resistance to clarithromycin in Helicobacter pylori. J Clin Microbiol 2003, 41(1):397-402.

10. Gerrits MM, van Vliet AH, Kuipers EJ, Kusters JG: Helicobacter pylori and antimicrobial resistance: molecular mechanisms and clinical implications. Lancet Infect Dis 2006, 6(11):699-709.

11. Morris JM, Reasonover AL, Bruce MG, Bruden DL, McMahon BJ, Sacco FD, Berg DE, Parkinson AJ: Evaluation of seaFAST, a rapid fluorescent in situ hybridization test, for detection of Helicobacter pylori and resistance to clarithromycin in paraffin-embedded biopsy sections. J Clin Microbiol 2005, 43(7):3494-3496.

12. van Doorn $L$, Glupczynski Y, Kusters JG, Megraud F, Midolo P, MaggiSolca N, Queiroz DM, Nouhan N, Stet E, Quint WG: Accurate prediction of macrolide resistance in Helicobacter pylori by a PCR line probe assay for detection of mutations in the $23 \mathrm{~S}$ rRNA gene: multicenter validation study. Antimicrob Agents Chemother 2001, 45(5):1500-1504.

13. Cambau E, Allerheiligen V, Coulon C, Corbel C, Lascols C, Deforges L, Soussy CJ, Delchier JC, Megraud F: Evaluation of a new test, genotype HelicoDR, for molecular detection of antibiotic resistance in Helicobacter pylori. J Clin Microbiol 2009, 47(11):3600-3607.

14. Almeida C, Azevedo NF, Iversen C, Fanning S, Keevil CW, Vieira MJ: Development and application of a novel peptide nucleic acid probe for the specific detection of Cronobacter genomospecies (Enterobacter sakazakii) in powdered infant formula. Appl Environ Microbiol 2009, 75(9):2925-2930

15. Perry-O'Keefe H, Stender H, Broomer A, Oliveira K, Coull J, Hyldig-Nielsen JJ: Filter-based PNA in situ hybridization for rapid detection, identification and enumeration of specific micro-organisms. J Appl Microbiol 2001, 90(2):180-189.

16. Stender H, Fiandaca M, Hyldig-Nielsen JJ, Coull J: PNA for rapid microbiology. J Microbiol Methods 2002, 48(1):1-17.

17. Cerqueira L, Azevedo NF, Almeida C, Jardim T, Keevil CW, Vieira MJ: DNA Mimics for the Rapid Identification of Microorganisms by Fluorescence in situ Hybridization (FISH). Int J Mol Sci 2008, 9(10):1944-1960.

18. Lehtola MJ, Torvinen E, Miettinen IT, Keevil CW: Fluorescence in situ hybridization using peptide nucleic acid probes for rapid detection of Mycobacterium avium subsp. avium and Mycobacterium avium subsp. paratuberculosis in potable-water biofilms. Appl Environ Microbiol 2006, 72(1):848-853.

19. Perry-O'Keefe H, Rigby S, Oliveira K, Sorensen D, Stender H, Coull J, HyldigNielsen JJ: Identification of indicator microorganisms using a standardized PNA FISH method. J Microbiol Methods 2001, 47(3):281-292.

20. Trnovsky J, Merz W, Della-Latta P, Wu F, Arendrup MC, Stender H: Rapid and accurate identification of Candida albicans isolates by use of PNA FISHFlow. J Clin Microbiol 2008, 46(4):1537-1540.

21. Guimaraes N, Azevedo NF, Figueiredo C, Keevil CW, Vieira MJ: Development and application of a novel peptide nucleic acid probe for the specific detection of Helicobacter pylori in gastric biopsy specimens. J Clin Microbiol 2007, 45(9):3089-3094.

22. Azevedo NF, Vieira MJ, Keevil CW: Establishment of a continuous model system to study Helicobacter pylori survival in potable water biofilms. Water Sci Technol 2003, 47(5):155-160.

23. Glupczynski Y, Broutet N, Cantagrel A, Andersen LP, Alarcon T, LopezBrea $\mathrm{M}$, Megraud F: Comparison of the $\mathrm{E}$ test and agar dilution method for antimicrobial suceptibility testing of Helicobacter pylori. Eur $J$ Clin Microbiol Infect Dis 2002, 21(7):549-552.

24. van Doorn LJ, Debets-Ossenkopp YJ, Marais A, Sanna R, Megraud F, Kusters JG, Quint WG: Rapid detection, by PCR and reverse hybridization, of mutations in the Helicobacter pylori $23 \mathrm{~S}$ rRNA gene, associated with macrolide resistance. Antimicrob Agents Chemother 1999, 43(7):1779-1782.

25. Kim JM, Kim JS, Kim N, Kim YJ, Kim IY, Chee YJ, Lee CH, Jung HC: Gene mutations of $23 \mathrm{~S}$ rRNA associated with clarithromycin resistance in Helicobacter pylori strains isolated from Korean patients. J Microbiol Biotechnol 2008, 18(9):1584-1589.

26. Garrido L, Toledo H: Novel genotypes in Helicobacter pylori involving domain $\mathrm{V}$ of the $23 \mathrm{~S}$ rRNA gene. Helicobacter 2007, 12(5):505-509.
27. Fontana C, Favaro M, Pietroiusti A, Pistoia ES, Galante A, Favalli C: Detection of clarithromycin-resistant Helicobacter pylori in stool samples. J Clin Microbiol 2003, 41(8):3636-3640.

28. Khan R, Nahar S, Sultana J, Ahmad MM, Rahman M: T2182C mutation in 235 rRNA is associated with clarithromycin resistance in Helicobacter pylori isolates obtained in Bangladesh. Antimicrob Agents Chemother 2004, 48(9):3567-3569.

29. Burucoa C, Garnier M, Silvain C, Fauchere JL: Quadruplex real-time PCR assay using allele-specific scorpion primers for detection of mutations conferring clarithromycin resistance to Helicobacter pylori. $J$ Clin Microbiol 2008, 46(7):2320-2326

30. De Francesco V, Zullo A, lerardi E, Giorgio F, Perna F, Hassan C, Morini S, Panella C, Vaira D: Phenotypic and genotypic Helicobacter pylori clarithromycin resistance and therapeutic outcome: benefits and limits. J Antimicrob Chemother 2010, 65(2):327-332.

\section{doi:10.1186/1471-2180-11-101}

Cite this article as: Cerqueira et al:: PNA-FISH as a new diagnostic method for the determination of clarithromycin resistance of Helicobacter pylori. BMC Microbiology 2011 11:101.

\section{Submit your next manuscript to BioMed Central and take full advantage of:}

- Convenient online submission

- Thorough peer review

- No space constraints or color figure charges

- Immediate publication on acceptance

- Inclusion in PubMed, CAS, Scopus and Google Scholar

- Research which is freely available for redistribution

Submit your manuscript at www.biomedcentral.com/submit
Biomed Central 